\title{
A Chamada de programação de TV, um estudo pelo enfoque das Teorias de Gênero
}

\author{
Cristina Teixeira Vieira de Melo ${ }^{1}$ \\ Universidade Federal de Pernambuco \\ cristinademelo@terra.com.br \\ Gustavo Henrique Oliveira de Almeida ${ }^{2}$ \\ Universidade Federal de Pernambuco \\ gustavopgc@yahoo.com.br
}

\begin{abstract}
Resumo: Este trabalho investiga o gênero 'chamada de programação de televisão'. Como a novela é um produto televisivo que apresenta diversidade de chamadas e a Rede Globo um importante centro mundial de produção de novelas, nosso corpus tem por base as chamadas de três novelas da referida emissora. Classificamos estas chamadas em 13 subcategorias distintas, em função de seu propósito comunicativo. Uma característica básica do gênero 'chamada de novela' é a polifonia, materializada na voz off do locutor e nos trechos de áudio e vídeo retirados da novela. Há ainda chamadas de novelas que apresentam forte carga de 'intertextualidade inter-gêneros', ou seja, simulam ser outro gênero textual com a finalidade de surpreender o público. Uma importante característica de qualquer tipo de chamada é o fato de estabelecer uma relação necessária com um 'gênero-fonte', pois, ela só existe para promover algum outro programa. Para tanto, vale-se da estratégia contração tempo/espaço, sintetizando em até $45 \mathrm{~s}$ os aspectos mais importantes de cada programa.
\end{abstract}

Résumé: Ce travail cherche à étudier le genre " appel de programmation de télévision ». Comme le feuilleton est un produit télédiffusé qui présente une diversité d'appels et que la Rede Globo en produit et en distribue mondialement, notre corpus cible les appels de trois feuilletons de la Globo. Nous avons classé ces appels en treize sous-catégories différentes, selon leur propos communicatif. Une caractéristique de base du genre " appel de feuilleton 》 est la polyphonie, matérialisée dans la voix off du locuteur et dans les fragments d'audio et de vidéo extraits du feuilleton. On constate aussi des appels fortement chargés "d'intertextualité inter-genres », c'est-àdire, qui simulent un autre genre textuel afin de surprendre le public. Une caractéristique importante de tout type d'appel vient du fait qu'il

\footnotetext{
${ }_{1}^{1}$ Professora Adjunto 1 da Pós-Graduação e do Departamento de Comunicação Social da UFPE. Doutora em Lingüística pelo Instituto de Estudos da Linguagem da UNICAMP. ${ }_{2}^{2}$ Mestre em Comunicação pelo Programa de Pós-Graduação em Comunicação da UFPE.
} 
établit une relation nécessaire avec un "genre-source ", étant donné qu'il n'existe que pour promouvoir quelque autre programme. Pour cela, il a recours à la statégie de la contraction temps/espace et synthétise en 45 s maximum les aspects les plus importants de chaque programme.

Summary: This work investigates the nature of "commercial break calls". As the soap-opera is a TV product that presents diversity of calls and the Net Globe is a very important worldwide center of soapopera productions, our corpus has its base on the calls of three soapoperas of this TV Channel. We classify them in 13 distinct subcategories, according to the intent of their communication. A basic characteristic of the soap-opera genre is the polyphony, materialized in the speaker's voice off over parts of audio and video of the TV drama. There are still commercial breaks' calls that present great and strong load of intertext between genres. They simulate to be another sort of genre, with the purpose to startle the public. An important characteristic of any type of these commercial breaks' calls is to establish a necessary relation with one "genre-source". Therefore, it only exists to promote another TV program. With that purpose it uses the strategy of contraction time/space, summarizing in 45 seconds or so, the most important aspects of each program.

Resumen: Este artículo examina el género "teaser de programación televisiva". Cómo la telenovela es un producto televisivo que apresenta una gran variedad de teasers y la Rede Globo es un importante centro mundial de producción de telenovelas, nuestro corpus se apoya en teasers de tres telenovelas de la dicha emisora. Clasificamos eses teasers em 13 subgrupos distintos, de acuerdo con su intención comunicativa. Una característica fundamental del género "teaser de telenovela" es la polifonía, hecha concreta por la voz en off del locutor y por los fragmentos de audio y video retirados de la telenovela. Hay también teasers de telenovela con fuerte carga de "intertextualidad intergéneros", es decir, que simulan ser otro género textual con la finalidad de sorprender el público. Una importante característica de cualquier tipo de teaser es el hecho de establecer una relación necesaria con un "género-fuente", pues él solamente existe para impulsar algun otro programa. Para eso, se aprovecha de la estrategia contracción tiempo/espacio, sintetizando en hasta 45 segundos los elementos más importantes de cada programa.

Mots-clé: Appel de Programmation, Télévision, Feuilleton, Genres Textuels.

Key-words: commercial break calls, television, soap-opera, textual genres.

Palavras-chave: Chamada de Programação; Televisão; Novela; Gêneros Textuais.

Palabras clave: Teaser de Programación; Televisión; Telenovela; Géneros Textuales. 


\section{Introdução}

Veiculada nos intervalos comerciais com o objetivo de promover os diversos programas de uma emissora, a chamada é um produto publicitário audiovisual, que, além da marca e do slogan da própria emissora, divulga para o telespectador nome, conteúdo, dia, horário e marca do programa a ser exibido.

O fato de os intervalos comerciais serem povoados por chamadas nos leva a afirmar que o principal produto que uma emissora anuncia é a própria emissora. Neste contexto, as chamadas têm uma enorme importância funcional e estratégica.

Por ser a líder de audiência no Brasil e ter criado um padrão de enorme sucesso de promoção dos seus programas, a Rede Globo foi a emissora escolhida para dar cabo a esta investigação. Vale salientar o alto investimento da Globo em recursos humanos e materiais para a produção das chamadas. Outro dado que mostra a importância do gênero chamada, na Globo, é o fato de existir, além da Divisão de Promoções, que produz as chamadas3, uma Divisão de Mídia de Chamadas, que pesquisa todos os números e estratos da audiência, definindo quais os espaços para melhor inserção de cada chamada ao longo da programação. Por exemplo, geralmente são exibidas duas chamadas por cada intervalo e em posições fixas - uma na abertura e a outra no encerramento do break comercial. A inserção de uma chamada logo na cabeça do break neutraliza um pouco o efeito zapping, fazendo com que o telespectador não mude de canal imediatamente e seja impactado pela chamada de programação. Já a veiculação de uma chamada no encerramento do intervalo comercial funciona não só para divulgar um outro programa, mas

\footnotetext{
3 De acordo com dados fornecidos pela própria Rede Globo, no ano de 2002, a Divisão de Promoções e a Divisão de Mídia de Chamadas tinham, juntas, cerca de 50 profissionais, o correspondente ao tamanho de muitas emissoras afiliadas da Globo pelo Brasil. Além disso, os equipamentos de gravação e edição de chamadas são os mais modernos do mundo, alguns produzidos sob encomenda para a Rede Globo.
} 
também como uma espécie de aviso de retorno ao programa interrompido, pois, graças à recorrência desse tipo de encaixe na grade de programação da Rede Globo, é possível afirmar que a audiência está condicionada a entender que o programa reiniciará.

Dentro da grande diversidade de programas promovidos pela Globo, as chamadas referentes ao programa "novela das oito" 4 foram escolhidas por ser a novela quem apresenta os maiores índices de audiência da TV brasileira e, especialmente, por ser este um tipo de programa que mantém uma linha de promoção completa (com vários tipos de chamadas), o que se mostra um modelo perfeito para o estudo proposto.

A pesquisa na qual se baseia este artigo5 investigou as chamadas das novelas Laços de Família, Porto dos Milagres e O Clone. De início, foram coletados mais de uma centena de scripts $^{6}$ de chamadas e mais de 50 cópias em vídeo de alguma delas, sendo escolhidas 6 (seis) de cada novela para compor o chamado corpus restrito da pesquisa. Neste texto, analisamos detalhadamente duas chamadas, além de comentarmos características sóciodiscursivas de todas as categorias investigadas.

Estudamos a chamada sob a ótica lingüística, observando-a como um evento sócio-discursivo. Ou seja, entendemos e apresentamos tal produto como sendo um gênero textual, um evento comunicativo recorrente na sociedade. Para tanto, utilizamos como aparato teórico os estudos sobre Gêneros Textuais e alguns conceitos da Análise do Discurso, mais

\footnotetext{
${ }^{4}$ Popularmente conhecida como "novela das oito" - pois, era veiculada a partir das 20:30h atualmente a novela 3, como é denominada no jargão interno da Programação da Rede Globo, é exibida a partir das $21 \mathrm{~h}$. Apesar disso, a emissora resolveu continuar explorando em suas chamadas o termo popular. Dessa forma, trabalharemos indistintamente com as duas expressões.

5 Este artigo resume as principais idéias da dissertação "O Gênero Chamada de Programação - uma investigação sobre as chamadas de novelas da Rede Globo", defendida pelo aluno Gustavo Almeida, sob orientação da professora Cristina Teixeira, no Programa Pós-Graduação em Comunicação da UFPE.

${ }^{6}$ São os textos com as "falas" do locutor, trechos de áudio e vídeo e outras informações relevantes para a produção das chamadas.
} 
especificamente os de dialogismo, polifonia, e intertextualidade. Para tanto, tomamos como referência os escritos de Bakthin (1979), Bronckart (1999), Maingueneau (2002) e Marcuschi (2003).

\section{Breve panorama teórico sobre os gêneros do discurso}

Partimos do pressuposto de que é impossível se comunicar verbalmente a não ser por algum gênero e por algum texto. Em outros termos, a comunicação verbal só é possível por meio de algum gênero textual7. Mikhail Bakhtin (1979) já dizia que cada esfera de utilização da língua elabora tipos relativamente estáveis de enunciados, sendo isso o que ele denominou de gêneros do discurso. E, como os gêneros textuais são fenômenos históricos, profundamente vinculados à vida social, sofrem influências da cultura na qual estão inseridos. Isso aponta para a multiplicidade e dinamicidade dos gêneros existentes, que nem sempre realizam-se da mesma forma ou obtém denominações unívocas de região para região; além disso, assim como surgem, podem desaparecer.

A riqueza e a variedade dos gêneros do discurso são infinitas, pois a variedade virtual da atividade humana é inesgotável, e cada esfera dessa atividade comporta um repertório de gêneros do discurso que vai diferenciando-se e ampliando-se à medida que a própria esfera se desenvolve e fica mais complexa. (Bakhtin, 1979: 279)

À determinada instância discursiva corresponde um conjunto de gêneros textuais que, às vezes, lhe são próprios ou, em certos casos, exclusivos. Por exemplo, a chamada de programação é um gênero pertencente a esfera da mídia, mais especificamente ao domínio da publicidade institucional. Sobre este aspecto pode-se relembrar a seguinte passagem de Bakhtin:

Cada esfera social conhece seus gêneros apropriados à sua especificidade, aos quais correspondem determinados estilos. Uma dada função (científica, técnica, ideológica, oficial, cotidiana) e dadas condições, específicas para cada uma das esferas da comunicação verbal, geram um dado gênero, ou seja,

7 Utilizamos como sinônimas as expressões gênero textual e gênero discursivo. 
um dado tipo de enunciado, relativamente estável do ponto de vista temático, composicional e estilístico. (Bakhtin, 1979: 284)

Ainda segundo Bakhtin, o indivíduo pode ignorar totalmente a existência teórica dos gêneros do discurso, mas, na prática, usa-os com segurança e destreza. Todos nós dominamos um saber intuitivo a respeito da adequação de textos em situações comunicativas. A este conhecimento e identificação dos inúmeros e diversificados gêneros, Maingueneau (2002: 43) denomina de 'competência genérica'. É neste sentido que os gêneros operam como geradores de expectativas de compreensão mútua. Por isto, Maingueneau afirma que o conhecimento de vários gêneros possibilita aos atores sociais uma economia cognitiva.

Mesmo não dominando certos gêneros, somos geralmente capazes de identificá-los e de ter um comportamento adequado em relação a eles. Cada enunciado possui um certo estatuto genérico, e é baseando-se nesse estatuto que com ele lidamos: é a partir do momento em que identificamos um enunciado como um cartaz publicitário, um sermão, um curso de língua etc., que podemos adotar em relação a ele uma atitude que convém. (Maingueneau, 2002: 44)

Muitas vezes, os gêneros textuais têm marcas lingüísticas mais ou menos estereotipadas e identificáveis. É o caso, por exemplo, das chamadas de estréia de novela que frequentemente contém o seguinte enunciado: "Estréia, hoje, depois do Jornal Nacional, a nova novela das oito...”. No entanto, devemos lembrar que conhecer um gênero não significa o domínio de uma forma lingüística, e sim, saber realizar lingüisticamente objetivos sociais específicos e particulares (Marcuschi, 2003). De fato, os gêneros textuais caracterizam-se muito mais por suas funções comunicativas, cognitivas e institucionais do que por suas peculiaridades lingüísticas e estruturais.

Uma outra característica dos gêneros do discurso é que mesmo apresentando alto poder preditivo e interpretativo das ações humanas em qualquer contexto discursivo, eles não são instrumentos estanques e 
enrijecedores da ação criativa. Caracterizam-se como eventos textuais altamente maleáveis, dinâmicos e plásticos. Surgem emparelhados a necessidades e atividades sócio-culturais, bem como na relação com inovações tecnológicas. Conforme Machado (2000: 68/9), “...por estarem inseridas na dinâmica de uma cultura, as tendências que preferencialmente se manifestam num gênero não se conservam ad infinitum, mas estão em contínua transformação no mesmo instante em que buscam garantir uma certa estabilização".

Bakhtin já falava na 'transmutação' dos gêneros e na assimilação de um gênero por outro, gerando novos. "O gênero sempre é e não é o mesmo, sempre é novo e velho ao mesmo tempo. O gênero renasce e se renova em cada obra individual de um dado gênero. Nisto consiste sua vida” (Bakhtin, 1979: 91).

Assim, podemos afirmar que, geralmente, um novo gênero surge ancorado em outros pré-existentes que se transmutam, ou seja, os gêneros são herdeiros históricos de outros gêneros. Por exemplo, a chamada de programação na televisão, como muitos outros gêneros deste veículo, tem como principal antecessor a chamada de rádio. Ainda hoje, ambas possuem algumas semelhanças e a mesma função sócio-midiática, mas, por estarem em suportes diferentes, são classificadas como gêneros distintos.

Esta ‘transmutação’ a qual se referia Bakhtin (1979), cria novas situações sócio-interativas, possibilitando o surgimento de novas relações no uso da linguagem, como as que caracterizam a oralidade e a escrita. As formas comunicativas próprias - os novos gêneros - que aparecem graças à essa hibridização, são também repletas, em sua maioria, de mais tipos integrados de semioses, como signos verbais, sons, imagens e formas em movimento (Marcuschi, 2003). Essa hibridização ou mescla de gêneros pode acontecer de tal forma que um gênero assume a função de outro. 
A intertextualidade inter-gêneros é justamente a "mescla de funções e formas de gêneros diversos num dado gênero" (Marcuschi, 2003: 31). Configura-se quando utilizamos a moldura de um gênero para formar um outro, com a finalidade específica deste último. Esta possibilidade de mesclagem entre vários gêneros é notada em diversas esferas sociais, mas é na publicidade que ela se mostra com grande destaque. Apesar desta hibridização, a garantia da comunicação se dá pelo fato de que, “como há um certo número de direitos e deveres associados ao gênero e que são conhecidos pelos falantes que compartilham daquele gênero, é possível fazer transgressões portadoras de sentido" (Maingueneau, 2002:64), sem deixar a comunicação escapar.

\section{Categorização das Chamadas em função do fluxo temporal da grade de programação}

Como vimos, apesar de serem relativamente estáveis do ponto de vista estilístico e composicional, os gêneros funcionam dentro de contextos sociais dinâmicos, por isto, podem alterar-se. No caso das chamadas de programação, verificamos que elas se desdobram em subcategorias, tendo em vista sua função sócio-comunicativa específica.

Como a chamada tem a finalidade de divulgar os programas da emissora seguindo o fluxo da grade horária da programação ${ }^{8}$, cada tipo de chamada

\footnotetext{
${ }^{8}$ Um dos mais influentes homens da televisão brasileira, Walter Clark, costumava enfatizar a importância da programação dizendo: "TV não é programa, é programação" (Clark, W. apud SOUZA, 2004: 53). De maneira clara e objetiva, programação é "o conjunto de programas transmitidos por uma emissora de televisão. O principal elemento da programação é o horário de transmissão de cada programa" (SOUZA, 2004: 54). A seqüência dos programas, o fluxo temporal diário, caracteriza a grade de programação, que é formada por todos os programas e seus respectivos horários. A programação tradicional de televisão se vale de dois conceitoschave - "a horizontalidade e a verticalidade na organização dos programas televisivos. A horizontalidade é a colocação de um programa ao longo da semana ou do mês, em um mesmo horário; e, a verticalidade, se traduz por uma seqüência ao longo do dia que vai sendo repetida semana a semana, mês a mês.” (BORELLI \& PRIOLLI (orgs.) 2000: 81). Essas são as características principais que permeiam as estratégias da televisão aberta para criar no telespectador o hábito de assistir aos seus programas. É nesse meio que encontramos a chamada de programação, importante produto televisivo que reforça os dois aspectos supracitados.
} 
apresenta elementos específicos, e vai se modificando ao longo do eixo temporal de um dia, uma semana, um mês, etc. Assim, as diferentes categorias de chamadas estão diretamente relacionadas à cronologia de sua veiculação na televisão, isto é, à sua temporalidade.

Encontramos em todas as chamadas a recorrência de uma dêixis ${ }^{9}$, que apresenta o fator da temporalidade como elemento funcional e norteador da produção e das estratégias de veiculação destes produtos. Isto significa que a cronologia é fundamental e interfere diretamente no conteúdo discursivo das chamadas. Nos trechos a seguir, por exemplo, o fluxo temporal é devidamente ressaltado pela locução off:

\section{Loc. Off: DIA PRIMEIRO, ESTRÉIA, A NOVA NOVELA DAS OITO...}

Loc. Off: NESTA SEXTA, ÚLTIMO CAPÍTULO DE...

Portanto, a temporalidade - e sua materialização lingüística, através de elementos dêiticos - é um fator de extrema importância no funcionamento sócio-discursivo das chamadas.

Tendo em vista o fluxo temporal da grade de programação, as chamadas de programação apresentam-se divididas nas seguintes categorias ${ }^{10}$ :

\footnotetext{
9 Dêiticos - ou embreantes - são elementos que marcam no enunciado, a situação de enunciação. (Maingueneau, 2002:108) Destacamos, principalmente, os dêiticos temporais e espaciais, que definem quando e onde se passa o fato.

10 As categorias de chamada listadas na tabela dizem respeito a todos os tipos de programas e não especificamente as de novelas, embora, por vezes, os comentários feitos enfatizem as deste gênero televisivo. Além disso, vale frisar que fora as categorias descritas no quadro, as chamadas são também classificadas - sob o ponto de vista do Departamento Comercial - em "spot" e "com patrocínio" (ou "com pat", ou ainda, com "rab", abreviatura de 'rabicho' comercial). A primeira significa que a chamada de determinado programa é exibida sem mensagem de patrocínio acoplada. A outra, como o próprio nome diz, é a chamada que tem acoplada a ela alguma mensagem de patrocínio do referido programa. São, portanto, determinações estritamente comerciais e que não alteram o conteúdo discursivo da chamada; elas recebem essa denominação juntamente com a denominação da categoria de produção, por exemplo: 'Chamada O Clone - Último Capítulo - Com Pat' ou 'Chamada Laços - Manut.
} 


\begin{tabular}{|c|c|}
\hline Categorias de Chamadas & Características \\
\hline Teasers & $\begin{array}{l}\text { Têm a finalidade de criar no telespectador } \\
\text { curiosidade e interesse, sem necessariamente } \\
\text { revelar qual é o programa que está sendo } \\
\text { anunciado. Normalmente, as chamadas desta } \\
\text { categoria apresentam forte característica de } \\
\text { intertextualidade entre gêneros. }\end{array}$ \\
\hline Lançamento & $\begin{array}{l}\text { Este tipo de chamada também cria expectativa, } \\
\text { mas já fornece informações básicas como o nome } \\
\text { do programa ou do evento - no caso das novelas, } \\
\text { apresenta o elenco. Há as chamadas de lançamento } \\
\text { que apresentam o elenco principal (nome e } \\
\text { imagem de cada ator/atriz) e as que apresentam os } \\
\text { nomes e as características principais dos } \\
\text { personagens. Estas chamadas também promovem } \\
\text { bastante a música-tema da novela. Neste tipo de } \\
\text { chamada é recorrente o uso da expressão 'Vem aí...' } \\
\text { seguida do nome do programa. }\end{array}$ \\
\hline Estréia & $\begin{array}{l}\text { Apresentam todos os detalhes do programa, } \\
\text { promovendo bastante o nome, o dia e o horário da } \\
\text { estréia. Costumam vir mescladas às de lançamento. } \\
\text { É corriqueiro o uso de expressões como 'Estréia' e } \\
\text { 'A nova novela das oito...', seguida dos nomes do } \\
\text { autor e da própria novela. A chamada de estréia é } \\
\text { constituída por cenas de diversos capítulos da } \\
\text { novela. As chamadas desta categoria têm seu } \\
\text { funcionamento apenas durante o período que } \\
\text { antecede a estréia, geralmente de um mês. } \\
\text { Percebemos ainda a intenção de tornar familiar ao } \\
\text { telespectador personagens e tramas da novela, } \\
\text { mostrando uma idéia geral do enredo. }\end{array}$ \\
\hline $\begin{array}{lll}\text { Início de } & \text { Temporada } & \text { de } \\
\text { Filmes/ } & & \\
\text { Eventos } & & \end{array}$ & $\begin{array}{l}\text { São chamadas especiais que promovem o início de } \\
\text { competições esportivas, de temporada de filmes, de } \\
\text { especiais de final de ano etc. Podem ser } \\
\text { semelhantes às de lançamento. Por exemplo, uma } \\
\text { recorrência padrão da Globo para as chamadas de } \\
\text { final de ano é apresentar no início da chamada a } \\
\text { expressão dêitica 'Fim de ano na Globo...' }\end{array}$ \\
\hline Manutenção Periódica & $\begin{array}{l}\text { Servem para lembrar ao telespectador o produto } \\
\text { promovido e divulgar o conteúdo específico dos } \\
\text { chamados 'programas especiais', que são aqueles } \\
\text { que não têm veiculação diária e sim semanal ou } \\
\text { esporádica, tais como programas de auditório, } \\
\text { partidas de futebol, shows artísticos, programas de } \\
\text { final de semana, etc. Uma série de expressões de }\end{array}$ \\
\hline
\end{tabular}

- Spot'. Neste último caso, é mais comum que o termo 'spot' seja omitido, isto é, geralmente, se não há a expressão "com pat" ou "com rab" significa que se trata de uma chamada 'spot'. 


\begin{tabular}{|c|c|}
\hline & $\begin{array}{l}\text { natureza dêitica caracteriza este tipo de chamada, } \\
\text { por exemplo, 'Próxima semana'; 'Em' + o mês; } \\
\text { 'Neste' + o dia da semana; 'Amanhã'; 'Hoje; 'Daqui, } \\
\text { a pouco'. Nas chamadas de programas 'Ao vivo' } \\
\text { encontramos também esta expressão (ao vivo) tal e } \\
\text { qual nas chamadas de transmissões esportivas, } \\
\text { como partidas de futebol, corridas de automóveis, } \\
\text { etc. }\end{array}$ \\
\hline Manutenção Diária & $\begin{array}{l}\text { Este é o tipo mais comum de chamada. Também } \\
\text { conhecida como chamada de sustentação ou } \\
\text { simplesmente 'manut', esta categoria tem a } \\
\text { finalidade de promover os detalhes mais } \\
\text { importantes de capítulos específicos dos programas } \\
\text { diários, como novelas, séries, minisséries, } \\
\text { telejornais, etc. Mais especificamente, os termos } \\
\text { recorrentes são: 'Nesta' + o dia da semana; } \\
\text { 'Amanhã' e 'Hoje'. Além destes, também se informa } \\
\text { o horário em que será veiculado o programa na } \\
\text { grade de programação, seja anunciando a hora } \\
\text { exata ou fazendo o que se poderia chamar de mais } \\
\text { uma auto-referência à emissora: quando a } \\
\text { chamada faz uso da expressão 'depois', } \\
\text { complementada com a menção do nome de um } \\
\text { determinado programa, por exemplo, 'Depois do } \\
\text { Jornal Nacional', "Depois do Programa do Jô". } \\
\text { Outra característica: a chamada de manutenção } \\
\text { diária "hoje" apresenta algumas das principais } \\
\text { cenas, especificamente, do episódio daquele dia. } \\
\text { Em geral, este tipo de chamada traz situações que } \\
\text { estão ocorrendo com mais longevidade durante a } \\
\text { novela e que costumam pertencer a uma ou várias } \\
\text { das tramas principais da novela. }\end{array}$ \\
\hline Institucionais & $\begin{array}{l}\text { Servem para campanhas de utilidade pública } \\
\text { ou de prestação de serviços à comunidade, e/ou, } \\
\text { ainda, para criar/manter a identidade da emissora. } \\
\text { Em geral, costumam promover o slogan da } \\
\text { emissora. }\end{array}$ \\
\hline Caronas & $\begin{array}{l}\text { São pequenas chamadas de, no máximo, } 7 \\
\text { segundos, que servem para promover as estréias de } \\
\text { novos programas. Elas são diferentes das de estréia } \\
\text { porque são dependentes de outras chamadas, pois } \\
\text { são exibidas acopladas às chamadas de outros } \\
\text { programas, como se estivessem "pegando uma } \\
\text { carona". }\end{array}$ \\
\hline $\begin{array}{l}\text { Últimos Capítulos/ } \\
\text { Final de Temporada }\end{array}$ & $\begin{array}{l}\text { Similares às 'manuts', estas chamadas têm a } \\
\text { finalidade de promover os episódios finais de } \\
\text { novelas, séries e miniséries. Diferem das anteriores } \\
\text { por apresentarem cenas mais importantes de }\end{array}$ \\
\hline
\end{tabular}




\begin{tabular}{|c|c|}
\hline & $\begin{array}{l}\text { momentos do desfecho da trama, conferindo ainda } \\
\text { mais destaque ao programa. As cenas, em geral, } \\
\text { são reveladoras e com uma carga melodramática } \\
\text { mais intensa. Juntamente com as cenas mais } \\
\text { impactantes do episódio, temos, por exemplo, para } \\
\text { maior reforço promocional, o destaque } \\
\text { videográfico para a expressão 'Último(s) } \\
\text { capítulo(s)'. }\end{array}$ \\
\hline Verticais & $\begin{array}{l}\text { Divulgam vários programas em uma só chamada. } \\
\text { Promovem os programas seguindo a temporalidade } \\
\text { do fluxo da grade horária verticalizada da } \\
\text { programação da emissora. }\end{array}$ \\
\hline $\begin{array}{l}\text { Inter-Programa (IP) ou } \\
\text { Pré-Censura }\end{array}$ & $\begin{array}{l}\text { São chamadas com duração máxima de } 15 \\
\text { segundos, exibidas exclusivamente entre um } \\
\text { programa e outro e que promovem o programa que } \\
\text { vai começar. Apresentam informações recorrentes } \\
\text { nas demais chamadas, como dia e horário, além do } \\
\text { nome do programa e a sua classificação etária - } \\
\text { por isso são conhecidas também como chamadas } \\
\text { de pré-censura. Também possuem características } \\
\text { de institucionais, pois sempre apresentam o nome } \\
\text { e o slogan da emissora. }\end{array}$ \\
\hline Áudio de Passagem de Bloco & $\begin{array}{l}\text { Estas chamadas contêm apenas locução em off, } \\
\text { duram, no máximo, } 7 \text { segundos e são veiculadas } \\
\text { sobrepostas à vinheta do programa que está sendo } \\
\text { exibido (apenas em novelas), no momento da ida } \\
\text { para cada break. }\end{array}$ \\
\hline Editoriais & $\begin{array}{l}\text { Denominamos chamadas editoriais as que são } \\
\text { feitas dentro dos programas de auditório, dos } \\
\text { telejornalísticos e das transmissões esportivas. } \\
\text { Geralmente são pequenos textos falados pelos } \\
\text { próprios apresentadores/narradores destes } \\
\text { programas. }\end{array}$ \\
\hline
\end{tabular}

\section{Coexistência da chamada com o 'gênero-fonte' e contração tempo/espaço}

Outra importante característica da chamada é o fato dela sempre estabelecer uma relação - necessária e constitutiva - com um outro gênero discursivo, o que denominamos aqui como 'gênero-fonte'11 ; ou seja, a chamada só pode existir a partir da existência de um outro gênero. Afinal de

\footnotetext{
${ }^{11}$ Como gênero-fonte das chamadas, entendemos todos os programas por elas promovidos em nosso caso, a novela das $21 \mathrm{~h}$ da Rede Globo.
} 
contas, a chamada só tem razão de ser com o objetivo de promover algum programa de determinada emissora. Ela existe porque existe algo a ser divulgado e promovido. Há sempre uma relação de coexistência entre a chamada e o gênero-fonte. Mas esta coexistência não é recíproca, isto é, existe dependência do gênero chamada com relação ao gênero-fonte, mas pode haver programa sem chamada na grade de programação.

Por sua vez, para a chamada promover um gênero-fonte ela se vale de uma estratégia a qual denominamos de contração tempo/espaço. A contração de tempo e espaço tem relação direta com o fato de os programas promovidos pelas chamadas - no caso, as novelas, ter em média 1 hora de duração, e as chamadas, por sua vez, costumam não ter mais de 45 segundos. Neste curto espaço de tempo, as chamadas precisam vender cada episódio da novela, apresentando algumas das melhores e mais importantes cenas do capítulo. É preciso, então, falar mais, dizendo menos. Neste sentido, percebemos que as cenas da novela selecionadas para aparecer numa chamada são aquelas que conseguem ilustrar melhor as tramas, costuradas pela locução em off.

\section{Análise das chamadas sob a perspectiva polifônica}

Encontramos claramente nas chamadas uma mescla de vozes que pode ser analisada a luz dos conceitos bakhtinianos de dialogismo e polifonia ${ }^{12}$, bem como pelos conceitos derivados de heterogeneidade, intertextualidade e interdiscursividade. Desta forma, nesta parte, nossa análise fundamenta-se especialmente na noção teórica de heterogeneidade discursiva, conceito desenvolvido por Authier-Revuz (1990) 13, e no fenômeno que Marcuschi

\footnotetext{
${ }^{12}$ Numa breve e pertinente distinção entre os termos dialogismo e polifonia, Barros (1997) distingue claramente entre dialogismo e polifonia, reservando o termo dialogismo para o princípio dialógico constitutivo da linguagem e de todo discurso e empregando a palavra polifonia para caracterizar um certo tipo de texto, aquele em que o dialogismo se deixa ver, aquele em que são percebidas muitas vozes na superfície textual.

13 Tomando por base os estudos de Bakhtin, Authier-Revuz (1990), fala em heterogeneidade mostrada e constitutiva. A heterogeneidade constitutiva equivaleria ao princípio do dialogismo bakhtiniano, constitutivo de todo discurso e de difícil localização na superfície textual. Já a heterogeneidade mostrada se apresenta de maneira mais clara nos textos. No
} 
(2003) vem chamando de intertextualidade inter-gêneros. Neste sentido, propomos a divisão das chamadas em dois grupos: a) Chamadas-cópia do gênero-fonte; b) Chamadas que usam a intertextualidade inter-gêneros.

\subsection{Chamadas-cópia do gênero-fonte}

Classificamos como chamadas-cópia do gênero-fonte aquelas formadas por cenas e trechos integralmente retirados das novelas. São chamadas que constituem o formato-padrão do gênero, compostas basicamente por uma combinação polifônica de trechos de locução off, trechos de áudio e vídeo, além de videografismo com os elementos de identidade visual da novela. Neste grupo, encontram-se as chamadas pertencentes, principalmente, às categorias 'estréia', 'manutenção' e 'últimos capítulos'. Neste tipo de chamada a heterogeneidade mostrada é facilmente identificada pelo analista.

Vejamos um exemplo de chamada-cópia e sua respectiva análise:

\begin{tabular}{|c|l|l|}
\hline TRECHO & \multicolumn{1}{|c|}{ VÍDEO } & \multicolumn{1}{|c|}{ ÁUDIO (textos + trilha) } \\
\hline A1 & $\begin{array}{l}\text { Rápido clipe com cenas de } \\
\text { praia. }\end{array}$ & Música-tema. \\
\hline A2 & $\begin{array}{l}\text { Cenas de Helena e filhos. } \\
\text { Videografismo: HELENA. }\end{array}$ & $\begin{array}{l}\text { Loc. Off: HELENA... SEMPRE COLOCOU } \\
\text { OS FILHOS EM PRIMEIRO LUGAR NA } \\
\text { SUA VIDA... }\end{array}$ \\
\hline A3 & $\begin{array}{l}\text { Trecho de áudio e vídeo } \\
\text { (A/V) da novela. Cena de } \\
\text { diálogo entre Helena e } \\
\text { Ivete. }\end{array}$ & $\begin{array}{l}\text { Helena p/ Ivete: “Meus filhos só tiveram } \\
\text { pai enquanto eram crianças. E um pai faz } \\
\text { falta, por pior que seja!” }\end{array}$ \\
\hline A4 & $\begin{array}{l}\text { Cenas de Helena, filhos e } \\
\text { Edu. } \\
\text { CAMILA. Videografismo: } \\
\text { Videografismo: FRED. }\end{array}$ & $\begin{array}{l}\text { Loc. Off: MAS AGORA QUE CAMILA E } \\
\text { FRED ESTÃO ENCAMINHADOS... ELA } \\
\text { SE ENTREGOU A UMA ARDENTE } \\
\text { PAIXÃO! }\end{array}$ \\
\hline A5 & $\begin{array}{l}\text { Trecho de A/V de diálogo } \\
\text { entre Edu e Helena. }\end{array}$ & $\begin{array}{l}\text { Edu p/ Helena: “Quem ama faz qualquer } \\
\text { coisa!” }\end{array}$ \\
\hline A6 & Cenas de Alma. & $\begin{array}{l}\text { Loc. Off: SÓ QUE ESSE SEU ROMANCE } \\
\text { VAI } \\
\text { ENFRENTAR }\end{array}$ \\
\hline
\end{tabular}

caso das chamadas, estes elementos mostrados podem ser facilmente percebidos, por exemplo, pela costura entre a voz do narrador e as falas 'literais' dos personagens. Trata-se, pois, em linhas gerais, de inscrever o ‘outro’ no discurso. 


\begin{tabular}{|c|c|c|}
\hline & Videografismo: ALMA. & $\begin{array}{l}\text { PRECONCEITOS... A COMEÇAR POR } \\
\text { ALMA... A TIA DO RAPAZ... }\end{array}$ \\
\hline A7 & $\begin{array}{l}\text { Trecho de A/V de diálogo } \\
\text { entre Alma e Edu. }\end{array}$ & $\begin{array}{l}\text { Alma } \mathrm{p} / \mathrm{Edu} \text { "Essa felicidade tem que } \\
\text { ficar restrita à cama daquela mulher. } \\
\text { Você tá me entendendo?? Nada mais do } \\
\text { que isso!!!" }\end{array}$ \\
\hline A8 & $\begin{array}{l}\text { Cenas de Edu e Estela. } \\
\text { Videografismo: EDU. } \\
\text { Videografismo: ESTELA. }\end{array}$ & $\begin{array}{l}\text { Loc. Off: ELA CRIOU OS SOBRINHOS } \\
\text { EDU E ESTELA COMO SEUS PRÓPRIOS } \\
\text { FILHOS... }\end{array}$ \\
\hline A9 & $\begin{array}{l}\text { Trecho de A/V de diálogo } \\
\text { entre Alma e Edu. }\end{array}$ & $\begin{array}{l}\text { Alma } \mathrm{p} / \mathrm{Edu}: \text { "Eu vivi até hoje pra você e } \\
\text { pra sua irmã!"” }\end{array}$ \\
\hline A10 & 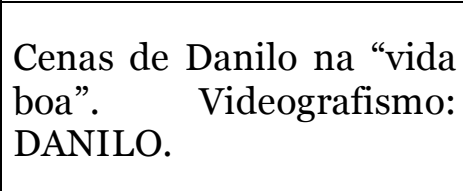 & $\begin{array}{l}\text { Loc. Off: É CASADA COM DANILO... UM } \\
\text { CARA QUE TEM ORGULHO DE NÃO } \\
\text { FAZER NADA... A NÃO SER AZARAR } \\
\text { MULHERES BONITAS... }\end{array}$ \\
\hline A11 & $\begin{array}{l}\text { Trecho de A/V de diálogo } \\
\text { entre Cíntia e sua mãe. }\end{array}$ & $\begin{array}{l}\text { Mãe p/ Cíntia: "Fica longe desse rapaz. A } \\
\text { Alma morre de ciúmes dele!" }\end{array}$ \\
\hline A12 & $\begin{array}{l}\text { Cenas de Cíntia. } \\
\text { Videografismo: CÍNTIA. }\end{array}$ & 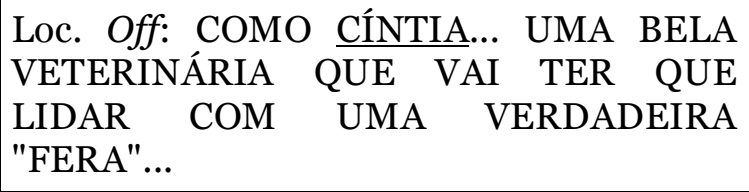 \\
\hline $\mathrm{A} 13$ & $\begin{array}{l}\text { Trecho de A/V de diálogo } \\
\text { entre Pedro e um outro } \\
\text { homem. }\end{array}$ & $\begin{array}{l}\text { A/V: Pedro } \mathrm{p} / \text { homem: "Ela que cuide do } \\
\text { trabalho dela e não se meta no meu!!” }\end{array}$ \\
\hline A14 & $\begin{array}{l}\text { Cenas de Pedro e de Íris. } \\
\text { Videografismo: PEDRO. } \\
\text { Videografismo: ÍRIS. }\end{array}$ & 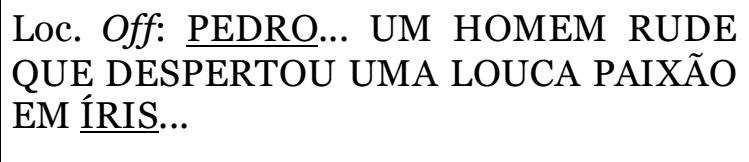 \\
\hline A15 & $\begin{array}{l}\text { Trecho de } \mathrm{A} / \mathrm{V} \text { da novela. } \\
\text { Cena de diálogo Íris e } \\
\text { Ingrid. }\end{array}$ & $\begin{array}{l}\text { A/V: Íris p/ Ingrid: "Homem casado não é } \\
\text { defunto, pode descasar!" }\end{array}$ \\
\hline A16 & Cenas de Íris. & $\begin{array}{l}\text { Loc. Off: UMA JOVEM COM UM AR } \\
\text { TODO ANGELICAL... } \\
\text { ESCONDE UM LADO PERVERSO... }\end{array}$ \\
\hline \multirow{3}{*}{ A17 } & \multirow{3}{*}{$\begin{array}{l}\text { Trecho de A/V da novela. } \\
\text { Cena de Î́ris com Aléssio. }\end{array}$} & A/V: Íris: "Helena" \\
\hline & & $\begin{array}{l}\text { A/V: Aléssio: "Ela é minha filha, tanto } \\
\text { quanto você!" }\end{array}$ \\
\hline & & $\begin{array}{l}\text { A/V: Íris: "Filha que há mais de } 20 \text { anos } \\
\text { não dá notícias, não é?!" }\end{array}$ \\
\hline A18 & Cenas diversas. & $\begin{array}{lllr}\text { Loc. } \quad \text { Off: } & \text { RELAÇÕES } & \text { FORTES... } \\
\text { DELICADAS... } & \text { DE } & \text { AMOR... } & \text { DE ÓDIO... }\end{array}$ \\
\hline
\end{tabular}




\begin{tabular}{|c|l|l|}
\hline \multirow{2}{*}{ A19 } & & DE PURA EMOÇÃO... \\
\cline { 3 - 4 } & $\begin{array}{l}\text { Cenas diversas da novela. } \\
\text { Videografismo: } \\
\text { AMANHÃ. } \\
\text { Videografismo: ESTRÉIA. }\end{array}$ & Loc. Off: AMANHÃ... ESTRÉIA... \\
\hline A20 & $\begin{array}{l}\text { Cenas diversas. } \\
\text { Videografismo: DIREÇÃO } \\
\text { RICARDO } \\
\text { WADDINGTON. }\end{array}$ & Loc. Off: DE MANOEL CARLOS... \\
\hline A21 & $\begin{array}{l}\text { Videografismo: vinheta } \\
\text { Laços de Família. }\end{array}$ & $\begin{array}{l}\text { Loc. Off: LAÇOS DE FAMÍLIA + Música- } \\
\text { tema. }\end{array}$ \\
\hline & Sem logomarca Globo. & \\
\hline
\end{tabular}

Identificamos em A1 a abertura da chamada com imagens de praia, ainda sem a recorrência da vinheta da novela, mas já com a trilha sonora específica. Esta trilha já tem uma representação institucional, pois aparecerá diariamente nas chamadas e nos capítulos da novela, servindo como elemento primeiro de referenciação e identificação.

Nos trechos A2, A4, A6, A8, A10, A12, A14 e A16, temos a locução off, que é um forte elemento mantenedor de unidade da promoção da programação e dos programas da Rede Globo, sobretudo, por se tratar da voz de um mesmo narrador ${ }^{14}$. O telespectador identifica com facilidade a voz deste narrador como sendo a voz oficial da emissora.

Os trechos de áudio e vídeo, A3, A5, A7, A9, A11, A13, A15 e A17 são cenas da novela com falas literais dos personagens, que funcionam, principalmente, para dar legitimidade à fala do narrador oficial na locução off. Os trechos de fala dos personagens reforçam o discurso do narrador off. Ou seja, a locução off anuncia um fato que vai acontecer ou que já aconteceu na

\footnotetext{
14 O locutor oficial das chamadas da Rede Globo se chama Dirceu Rabello e ocupa esta função desde o início da década de 1970. É a voz (fisiológica) da emissora.
} 
novela e o trecho A/V - discurso reportado - confirma o dito, mostrando parte deste fato.

\subsection{Chamadas que usam a intertextualidade inter-gêneros}

Já vimos que a intertextualidade inter-gêneros é uma característica de hibridismo apresentada por alguns gêneros textuais. Uma mescla que faz com que determinados gêneros assumam o formato de outros. $\mathrm{O}$ investimento de um certo gênero em outro quadro comunicativo e funcional, que não o seu de origem, causa um estranhamento no interlocutor, chamando sua atenção. $\mathrm{Na}$ publicidade, "desenquadrar o produto do seu enquadre normal é uma forma de enquadrá-lo em novo enfoque, para que o vejamos de forma mais nítida no mar de ofertas de produtos." (Marcuschi, 2003: 32).

Geralmente, do ponto de vista da temporalidade, as chamadas que apresentam intertextualidade entre gêneros são produzidas para serem exibidas antes da estréia da novela, portanto, costumam pertencer às categorias de 'teaser' e de 'lançamento'.

A seguir, apresentamos em exemplo de chamada que possui forte carga de intertextualidade entre gêneros.

\begin{tabular}{|c|c|c|}
\hline \multicolumn{3}{|c|}{$\begin{array}{c}\text { Chamada 'B' } \\
\text { MILAGRES - MANUTENÇÃO - ELEIÇÕES } 1\end{array}$} \\
\hline TRECHO & VÍDEO & ÁUDIO (textos + trilha) \\
\hline $\mathrm{B} 1$ & Marca Porto dos Milagres & \\
\hline B2 & $\begin{array}{l}\text { Ilustração videográfica de } \\
\text { uma cartela azul com } \\
\text { caracteres brancos } \\
\text { escrito: } \\
\text { Eleitoral de Porto dos } \\
\text { Milagres. Lei no } 9.605 \text { " }\end{array}$ & \\
\hline B3 & $\begin{array}{l}\text { Cena do candidato Félix } \\
\text { Guerrero em uma } \\
\text { bancada, com a marca do } \\
\text { PDV, "Partido da } \\
\text { Vanguarda Democrática" } \\
\text { no canto superior direito }\end{array}$ & $\begin{array}{l}\text { Félix: "NÃO SE DEIXE ENGANAR PELA } \\
\text { CAMPANHA MENTIROSA DA DA } \\
\text { OPOSIÇA, EU NAO PROMETO APENAS, } \\
\text { EU CUMPRIREI, SE FOR ELEITO VAI } \\
\text { TER COMIDA NA SUA MESA, ESCOLA } \\
\text { PARA OS SEUS FILHOS, TRABALHO }\end{array}$ \\
\hline
\end{tabular}




\begin{tabular}{|c|c|c|}
\hline & $\begin{array}{l}\text { do vídeo e um crédito de } \\
\text { rodapé "Félix Guerrero". }\end{array}$ & $\begin{array}{l}\text { PARA TODOS, NÃO ME DEIXEM SÓ, } \\
\text { VOTEM EM MIM.” }\end{array}$ \\
\hline B4 & $\begin{array}{l}\text { Clipe com jingle de } \\
\text { campanha eleitoral onde } \\
\text { o candidato Félix } \\
\text { Guerrero aparece nas } \\
\text { ruas abraçando } \\
\text { populares, em comício, } \\
\text { beijando crianças, } \\
\text { inaugurando obras, nos } \\
\text { braços do povo. }\end{array}$ & $\begin{array}{l}\text { Letra do jingle: “ELE É COMPANHEIRO, } \\
\text { ELE É FÉLIX, É GUERREIRO. VOTO ELE } \\
\text { TEM, ELE É NOSSO PAINHO. ELE VAI } \\
\text { ALEGRAR O NOSSO TERREIRO, FÉLIX } \\
\text { GUERRERO.” }\end{array}$ \\
\hline B5 & \multicolumn{2}{|l|}{ Fade. } \\
\hline B6 & $\begin{array}{l}\text { Cena do candidato Guma } \\
\text { em uma bancada, com a } \\
\text { marca do PCT, "Partido } \\
\text { das Causas Trabalhistas" } \\
\text { no canto superior direito } \\
\text { do vídeo e um crédito de } \\
\text { rodapé "Gumercindo } \\
\text { Vieira". }\end{array}$ & 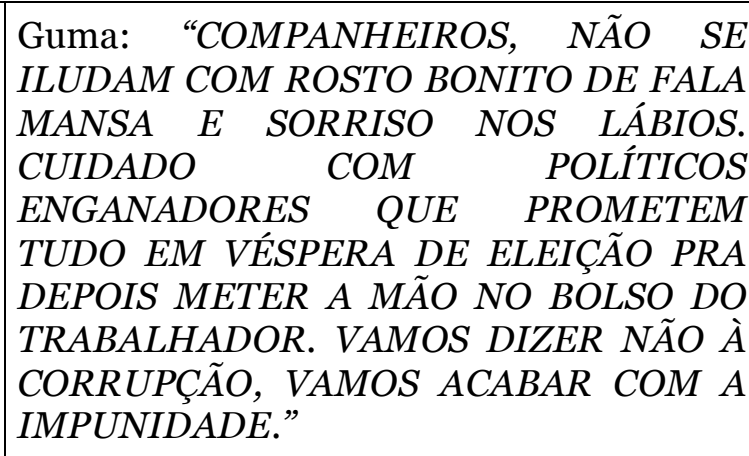 \\
\hline B7 & $\begin{array}{l}\text { Clipe com jingle de } \\
\text { campanha eleitoral onde } \\
\text { o candidato Guma } \\
\text { aparece nas ruas fazendo } \\
\text { protesto } \\
\text { trabalhadores rurais, } \\
\text { populares, etc. }\end{array}$ & $\begin{array}{l}\text { Letra do jingle: "DEIXA O POVO FALAR, } \\
\text { DEIXA O POVO ESCOLHER, O POVO VAI } \\
\text { VENCER, O POVO VAI GANHAR, O REI } \\
\text { TRABALHA PRA TIRAR, GUMA, GUMA, } \\
\text { GUMA, VAI GANHAR!" }\end{array}$ \\
\hline B8 & Marca Porto dos Milagres & Música-tema da novela. \\
\hline
\end{tabular}

Temos, em B1, uma rápida aparição da marca da novela Porto dos Milagres. Esta aparição é muito mais efêmera que as vinhetas das chamadas convencionais, o que nos leva a inferir que não era interesse mostrá-la e que ela só foi colocada para não descaracterizar por completo o gênero.

No trecho B2, surge uma cartela videográfica com informações sobre o produto e um número de lei. Esta é uma recorrência que caracteriza o gênero horário eleitoral gratuito em emissoras de rádio e televisão. No Brasil, a informação deve ser fornecida ao público antes da exibição do programa, 
devendo constar o número da lei federal referente, no caso a lei eleitoral de número 9.605.

Em B3, aparece o ator Antônio Fagundes, no papel do personagem da novela Porto dos Milagres, Félix Guerrero - que no período da exibição desta chamada estava participando de um processo eleitoral na novela, concorrendo ao cargo de prefeito da cidade-cenário. 'Guerrero' está fazendo um pronunciamento à população, sentando atrás de uma bancada e à frente de um painel tendo ao seu lado o símbolo do partido e seu nome em crédito no rodapé do vídeo. Neste pronunciamento, o candidato, de posição situacionista, profere um discurso com enunciados notadamente utilizados por políticos da situação, com acusações e ofensas gratuitas ao opositores "Não se deixe enganar pela campanha mentirosa da oposição...".

O próximo trecho - $\mathrm{B}_{4}$ - apresenta mais um aspecto de inter-gêneros, o videoclipe de um jingle eleitoral, com imagens do candidato sorridente inaugurando obras, cumprimentando o povo nas ruas e uma música repleta de rimas fáceis. Este trecho se encerra com uma tela preta - fade - fazendo uma ligeira transição para o outro candidato.

O candidato da oposição, representado pelo ator Marcos Palmeira, aparece a partir do trecho $\mathrm{B} 6$, na mesma estrutura estética videográfica e lingüística anterior, diferenciando-se pela postura e discurso característicos dos candidatos oposicionistas. Percebemos nova referência intertextual ao mundo real em "Companheiros, não se iludam com rosto bonito de fala mansa e sorriso nos lábios...", a expressão destacada remete imediatamente ao então virtual candidato à presidência da República, Luís Inácio da Silva e ao Partido dos Trabalhadores, através, também, do nome do partido da trama "Partido das Causas Trabalhistas". Novamente há um jingle e um clipe com imagens similares às do candidato anterior, ratificando a disputa eleitoral. 
Finalmente, em B8, a marca da novela, reaparece no encerramento com a mesma rapidez do início, sendo assim, a única característica básica do gênero chamada presente no produto.

Neste exemplo, percebemos que, apesar das mudanças, o propósito comunicativo do gênero chamada é preservado, ou seja, mesmo mudando a forma, a finalidade sócio-comunicativa de sensibilizar o telespectador a consumir o produto promovido, não se perde.

\section{Considerações finais}

Apesar de termos conseguido elencar 13 (treze) diferentes tipos de chamadas, cada uma delas diretamente relacionadas à cronologia de sua veiculação na televisão (estréia, lançamento, últimos capítulos etc), todas elas se configuram sob um grande gênero guarda-chuva, devidamente reconhecido pelo público como 'chamada'.

Para que este reconhecimento aconteça, se faz necessária uma relativa estabilidade sócio-discursiva do gênero através da permanência da função comunicativa balizadora da chamada, que é promover os programas da grade de programação de uma emissora e, paralelamente, estabelecer rotinas objetivando fazer com que a audiência assista aos programas promovidos. Além disso, há uma estruturação relativamente estável de enunciados que se materializa, muitas vezes, na presença e repetição de expressões dêiticas como “nesta segunda”, “estréia”, “a nova novela das oito”, “vem aí”, “depois do Jornal Nacional”.

Outra importante característica da chamada é o fato dela sempre estabelecer uma relação com um outro gênero, o 'gênero-fonte'. Afinal de contas, a chamada só tem razão de ser com o objetivo de promover algum programa de determinada emissora. Por sua vez, para a chamada promover um gênero-fonte ela se vale de uma estratégia a qual denominamos de contração tempo/ espaço. Tal e qual um trailer de filme de cinema, a chamada 
precisa sintetizar, em pouquíssimo tempo, os aspectos mais importantes de cada programa.

Além das características já citadas: herança sócio-histórica, finalidade comunicacional voltada para a promoção de programas, recorrências lingüístico-discursivas, necessária relação da chamada com um gênero-fonte e contração de tempo/espaço, encontramos claramente nas chamadas uma mescla de vozes que pôde ser analisada a luz dos conceitos de dialogismo e polifonia, heterogeneidade, e intertextualidade.

De fato, as chamadas são constituídas essencialmente por uma combinação polifônica de enunciados. Constatamos isto até mesmo no seu formato-padrão, que apresenta um conjunto de trechos de locução off, corporificada na voz institucional de um narrador onisciente e onipresente, a quem cabe narrar a 'história', 'costurando-a com trechos de áudio e vídeo, originalmente retirados da novela para reforçar e dar legitimidade a fala do narrador. Estes aspectos são exemplos claros de discursos relatados diretos e indiretos que configuram a heterogeneidade mostrada de Authier-Revuz (1990).

Além disso, encontramos e analisamos chamadas que apresentam forte carga de intertextualidade inter-gêneros (Marcuschi, 2003), ou seja, chamadas que, com a finalidade de causar um estranhamento e, assim, chamar atenção do público, simulam, essencialmente através da reprodução do formato, ser outros gêneros do discurso.

Notamos, portanto, que os produtores têm promovido mudanças significativas na forma do gênero chamada de programação, preservando, porém, o seu propósito sócio-comunicativo. Isso comprova mais uma de nossas hipóteses iniciais: mesmo variando em formato, a chamada preserva sua função, o que nos permite continuar caracterizando-a como gênero chamada de programação. 
Após estudar a complexidade e importância das chamadas de programação da Rede Globo, ficamos tentados a afirmar que a chamada de programação é o mais importante produto de divulgação dos programas da referida emissora, é o seu principal comercial.

Por fim, mostramos também ser correto afirmar que as chamadas seguem regras básicas e padronizadas no que se refere ao seu funcionamento discursivo, constituindo-se, assim, gêneros do discurso.

\section{Referências Bibliográficas}

AUTHIER-REVUZ, Jaqueline. 1990. "Heterogeneidades(s) enunciativa(s)". Trad: Celene M. Cruz e João Wanderley Geraldi. In: Cadernos de Estudos Lingüísticos, 19. Campinas. IEL/Unicamp. pp. 25-42.

BAKHTIN, Mikhail. 1979. Estética da criação verbal. São Paulo: Martins Fontes.

BARROS, Diana Luz Pessoa de. (1994). "Dialogismo, Polifonia e Enunciação". In: Barros, D. L. P. de \& Fiorin, J. L. (orgs) In: Dialogismo, Polifonia e Intertextualidade. São Paulo: EDUSP. pp. 01-27.

BORELLI, Sílvia \& PRIOLLI, Gabriel. (coords.) 2000. A Deusa Ferida. Por que a Rede Globo não é mais a campeã absoluta de audiência. São Paulo: Summus Editorial.

BRONCKART, Jean-Paul. 1999. Atividade de linguagem, textos e discursos: por um interacionismo sócio-discursivo. São Paulo: EDUC.

MACHADO, Arlindo. 2000. A televisão levada a sério. São Paulo: Editora SENAC.

MAINGUENEAU, Dominique. 2002. Análise de Textos de Comunicação. São Paulo: Cortez Editora.

MARCUSCHI, Luiz Antônio. 2003. "Gêneros Textuais: Definição e Funcionalidade.” In BEZERRA, M. A. DIONISIO, A. P. MACHADO, A. R. (orgs.) Gêneros Textuais \& Ensino. Rio de Janeiro: Lucerna. pp 19-36.

SOUZA, J. C. Aronchi. 2004. Gêneros e formatos na televisão brasileira. São Paulo. Summus Editorial. 